\title{
The emerging pattern of disability in Rwanda
}

\author{
Vyvienne R. P. M'kumbuzi ${ }^{1,2}$, J.-B. Sagahutu' ${ }^{2}$, J. Kagwiza ${ }^{2}$, G. Urimubenshi' ${ }^{2}$, and K. Mostert-Wentzel ${ }^{3}$ \\ 'University of Malawi College of Medicine, Physiotherapy Department, Blantyre, Malawi ${ }^{2}$ Kigali Health Institute, Physiotherapy Department, Kigali, \\ Rwanda, and ${ }^{3}$ University of Pretoria, Physiotherapy Department, Pretoria, South Africa
}

\begin{abstract}
Purpose: The purpose of this paper is to describe the emerging pattern of disability (activity limitation) in terms of its prevalence, age and gender distribution in Rwanda. Method: A door-to-door survey was conducted in all households in villages from two districts selected through a multi-stage sampling procedure. Identified persons were screened for activity limitations using age-appropriate instruments developed from domains in the ICF. Proportions were computed and disaggregated by age group, gender, district and activity limitation. A multidisciplinary rehabilitation team including community members participated in the development of instruments, community mobilisation, data collection and collation. Results: Prevalence rates of $8.6 \%$ (Bugesera) and $14.7 \%$ (Musanze) were obtained. The prevalence of disability was higher in adults than in children in both districts $(10.4 \%$ versus $6.6 \%$ in Bugesera and $19.6 \%$ versus $7.7 \%$ in Musanze). Visual limitations occurred the most frequently in both adults and children in both districts. Mobility and mental health limitations also notably contributed to the overall disability burden. Conclusion: The prevalence of disability obtained was higher than all previously reported data for Rwanda. Despite the limitations, the findings provide useful information for planning rehabilitation services and to direct future enquiry into the epidemiology of disability in Rwanda.
\end{abstract}

Keywords: Community-survey, Prevalence of disability, Rwanda

$>$ Implications for Rehabilitation

- It is important to design specific surveys to measure disability using contemporary methods to gauge the situation accurately and qualitatively.

- Currently, the ICF provides the best framework to describe the epidemiology of disability meaningfully; it enables comparisons within and between countries and regions of the world; and enables the active participation of a wide range of rehabilitation stakeholders including PWDs and lay community members.

- The vast majority of disabilities in Rwanda are limitations in visual, mobility and mental health functions.

\section{Introduction}

"More than one billion people in the world live with some form of disability. Of this number, nearly 200 million experience considerable difficulties in functioning. In the years ahead, disability will be an even greater concern because its prevalence is on the rise" [1]. In 2011, the World Health Organization (WHO) the methodology an published the "World Report on Disability", a seminal quality of data collection to identify those with a disability [2-4]. publication. This publication included a revision of our knowledge Methods that result in lower prevalence figures for on the prevalence of the number of people living with some form disability include tools in which a person self identifies as being of disability from around $10 \%$ to $15 \%$ [1]. The overall rate is only disabled, prevalence estimates based on only diagnosable one reflection of disability prevalence as the patterns of disability conditions, and estimates based on the actual performance of are acknowledged to vary considerably between and even activities of daily living (ADLs). These methodologies result in problems when cross-national comparisons are attempted [4]. For example, in the 1990 Zambian census the question "Do you have a disability?', question yielded a level of disability of only $1 \%$ [5]. In contrast, a function-based approach, using the Address for correspondence: Vyvienne R. P. M'kumbuzi, University of United Nations Washington Group Questions in conjunction Malawi, College of Medicine, P. Bag 360, Chichiri, Blantyre 3, Malawi. with more detailed survey questions, yielded a disability Tel: $\quad+265996151168$. E-mail: vyvienne2006@yahoo.co.uk prevalence of over 13\% [5]. 
Using data from a national Census is a common approach to generating disability estimates. Since the methodology in collecting census data and in particular disability-based census data differ, the estimates generated tend to be incomparable [2]. In addition, the questions of a census do not capture the richness of human functioning inherent in current definitions of disability and models of disability - either by type of disability (physical, mental, sensory, and psychological) or by functional domain (body structure/function, activities, and participation). This is especially true in a social model of disability where disability arises from the interaction between functional status and the environment [6]. A further disadvantage of census data is the focus on physical disability resulting in an underestimate of disability due to mental health [2].

Compared to a census, small local surveys tend to report higher rates of disability. This finding may be because of the ability to generate questions with greater detail and to ask more questions that relate specifically to disability [5]. Small local surveys may also underestimate some forms of disability as people may not report socially stigmatized conditions [7]. Despite these shortcomings, a census-based approach is still largely used for the purposes of international comparison of disability prevalence, because in low-income countries, it is often the only source available.

\section{Disability in Rwanda}

In Rwanda, the definition of disability is legislated by the national government [8] and defined as "the condition of a person's impairment of health ability he or she should have been in possession, and consequently leading to deficiency compared to others" [6]. In the 2002 national census in Rwanda, persons with disabilities (PWDs) were defined as: "Persons who were born without physical, mental or psychological ability like that of others or who were deprived of it due to illness, accident, war or old age" [9]. The most common types of disability were categorised by statisticians as belonging to the "upper limb", "lower limb", "others", "deaf/dumb", "mental deficiency", "blind", and "trauma" [9]. The outcome of this census was a national prevalence estimate of disability of $4.7 \%$. We believe that this figure is likely to be an underestimate since the census methodology incorporated a number of problems inherent in this type of data collection. First, it is known that there is a stigma attached to disability in Rwandan society that may have inhibited some households from declaring members with a disability $[7,10]$. Second, the government relied on self-identification of disability [4] and third, disability was ill defined [6].

\section{Statement of the problem}

Data pertaining to the magnitude of disability in Rwanda is currently census-based. It does not take into account the current conceptualization of disability, which defines human functioning according to activity limitations, participation restrictions and the interaction of the people with disabilities (PWDs) with the environment. Disability is crudely categorized, and the census does not disaggregate the statistics of PWDs by age.

\section{Purpose and significance}

The purpose of this article is to offer an alternative methodology to the current Rwandan government's approach to estimating the prevalence of disability. We describe the pattern of disability in terms of its prevalence, age and gender distribution, as well as by type of activity limitation. By so doing, this paper describes an attempt to overcome previous shortcomings and to arrive at a more accurate prevalence of disability in Rwanda.

We planned to achieve this broad objective by defining disability using the concept of activity limitation; and by actively harnessing the participation of PWDs, their families and their communities. The extent, to which both underpinnings are elaborated in this paper, is a first for Rwanda. The data obtained was collected as baseline surveys in two independent districts prior to implementing Community-based Rehabilitation (CBR).

In 2006, the UN adopted the International Convention on the Rights of PWDs, and many governments and international development agencies are turning their attention to the goal of including PWDs in socio-economic development initiatives [2]. Rwanda ratified the UN Convention on the Rights of PWDs in 2008 [11]. In addition, there is a growing acknowledgement that unless PWDs are included in social and economic development programmes, realization of the Millennium Development Goals (MDGs) will remain elusive [12]. Accurate data on disability is required to enable processes that aim to satisfy these obligations.

It is hoped that this article will be of use to the government of Rwanda, development partners, international and local nongovernmental organizations (NGOs) and Disabled Persons Organizations (DPOs), to take forward the work of rehabilitation of PWDs in Rwanda. We also believe that the findings may also provide insights for other low-income countries on the continent and beyond with a similar socio-economic and geo-political history.

\section{Method}

\section{Setting, population and sampling}

The study was conducted in two villages (Biryogo and Karama) in Bugesera district in the Eastern province of Rwanda, and in two villages (Gataba and Gasenyi) in Musanze district in the Northern Province of Rwanda.

A multi-stage sampling method was employed. Purposive sampling of the Northern and Eastern provinces was conducted, based on anecdotal data suggesting that these two provinces may have great need for CBR. Subsequently, purposive sampling was employed to select one district in each of the two provinces. Musanze and Bugesera were selected primarily because the Ministry of Local Government (MINALOC) had demonstrated a willingness to meet the needs of PWDs through an organized program; secondly, the district hospital that was expected to sustain the CBR program could provide technical support, buttressed by the technical and financial support of development partners in the district who were willing to integrate PWDs into their developmental activities.

At the sub-district levels (sectors, cells and villages) representatives of PWDs together with MINALOC selected study sites by considering the following criteria: communities that were unable or had difficulty to access rehabilitation services (geographically isolated); communities with PWDs that could benefit from $\mathrm{CBR}$ and communities with community health workers that were willing to expand their scope of work to include follow up of PWDs.

Therefore, selection of the villages was done in collaboration with MINALOC (the mayor, vice mayor for social affairs, education officer, officer responsible for health and social welfare in the district and a representative of the PWDs). The investigators also involved appointed sector- and cell leaders in this process. All households in the selected villages were included in the survey. 


\section{Instrumentation}

There were four instruments used to collect data.

(1) Profile of the CBR Area. This survey was adapted from an instrument contained in the manual on Guidelines for Implementing CBR in Zimbabwe [13]. It was used to profile the villages and district where data was collected in terms of population characteristics, education, health and rehabilitation services, economic activities and resource persons' for rehabilitation activities.

(2) Home Entry Questionnaire. The research team and the district community health workers developed this questionnaire collaboratively. It considered a culturally acceptable approach to enter homes as "strangers" - to acquaint the researchers with the home dwellers, familiarize the home dwellers with the purpose of the visit and intent of the study. The home entry questionnaire was developed to verify the population data previously obtained from the Profile on CBR area from MINALOC. Hence head count disaggregated by gender and age group was recorded on the questionnaire to later serve as denominator data for computing prevalence rates.

(3) Adult (more than 18 years) and child ( 0 to 18 years) disability screening tools were developed based on activity limitations section of the International Classification of Functioning, Disability and Health (ICF). Community members and community health workers assessed face validity of tool content. The child screening tool contained age-appropriate questions for children about tasks including feeding/suckling and learning difficulties. Age appropriate developmental milestones were also taken into account for example for sitting, crawling and walking. Thus in all villages in this survey, the concept of activity limitation was the definition of disability. The screening tools also collected the socio-demographic data of the PWDs and their caregivers.

(4) Rehabilitation Assessment Form. This form was used to conduct detailed and comprehensive clinical and rehabilitation assessments of PWDs. This was adapted from the regular and standardized assessment tools used by the various rehabilitation personnel conducting the assessments in their usual place of work. Hence it sought to document the client's histories, identify the client's problems and underlying causes, and to tailor and institute a rehabilitation management plan (including referral).

All instruments were available in English. The home entry questionnaire and the disability screening tools were translated into Kinyarwanda, using a consensus methodology in a workshop that involved community health workers, the village chiefs, participating rehabilitation technical experts and the researchers. Four group field trials (two in each district) were undertaken to test the validity and applicability of all the instruments.

\section{Procedure}

Ethical clearance was obtained from the Kigali Health Institute Institutional Review Board in 2010. Permission for entry into each district was obtained from the mayor of the respective district, and from the sector leaders as is the practice in Rwanda. Community consent for the door-to-door survey was obtained at a community meeting prior to the survey. Data was collected between 23 and 27 August 2010, in Musanze and between 26 and 30 September 2011, in Bugesera.

Data collection involved a 4 phase process.

Phase 1 - Social mobilization and awareness raising campaign. This included interactive audio-visual and multi-media presentations defining disability, its causes, rehabilitation services available and the role of the community and organizations representing PWDs in meeting the needs of PWDs. Technical experts (physiotherapy, orthopedic technology, ophthalmology, mental health, education and social welfare officers) addressed the community at a meeting held for all members of the community at each study site. The purpose of this phase was to demystify and de-stigmatize disability and to facilitate community participation in the door-to-door survey and especially to limit barriers to accessing PWDs during the survey at the household level.

Phase 2 - Training of research assistants. Community Health Workers (CHWs) and rehabilitation professionals were the research assistants. They were trained to identify, screen and refer PWDs during the survey. They were also expected to continue performing these functions as part of the CBR programme after completion of the survey. All research assistants had been involved in developing the instruments for identification, screening and referral of PWDs.

Phase 3 - Research assistants were grouped. At least one $\mathrm{CHW}$, one physiotherapist and a rehabilitation technical expert constituted a group. The CHWs facilitated entry into each home, as they were drawn from the community and had participated in transect mapping, the CHWs were familiar with the geography of the village, and were also familiar with households where PWDs lived. The rehabilitation technical expert ensured quality of the disability screening process and also took the opportunity to observe the environment in which the PWDs lived for future use in rehabilitation services planning. Two physiotherapy students were attached to each group for training purposes.

Each group was allocated transects of the village to conduct the door-to-door survey. Data collection took place within the home (kitchen or living room) or within the home's immediate environs, outdoors. At each house, the home entry questionnaire was administered first. From this questionnaire the research determined the number of adults and children in the household. The head or most senior member of the household responded to the home entry questionnaire. Asking activity limitation questions using the adult or child disability-screening tool as appropriate for each member reported to be living in that household followed this step. The adult member being surveyed, the head of the household, the caregiver or most senior member of the household present during the survey was the primary respondent. The latter three were selected if the member being surveyed was a child, was reportedly mentally unwell or if the member was absent on the survey day. Where necessary other members of the household present were allowed to participate in responding to clarify the activity limitation. Those PWDs reported to have one or more limitations in the domains on the screening tools were examined for limitations in the domains reported to verify the reports. At households where no member was present and the house closed, the same procedure was used but with the neighbour as the primary respondent assisted by the $\mathrm{CHW}$ on the research team. The two screening tools were therefore used to identify PWDs with a disability.

Phase 4 - Rehabilitation assessment and plan, and follow-up arrangements. Identified persons were invited to a pre-arranged central outreach point to undergo a comprehensive rehabilitation assessment by professionals on the next day. A mobile clinic also conducted home visits where PWDs had indicated they would be unable to visit the outreach point. Specialised clinics were set up at the outreach point - mobility, ophthalmology, mental health, medical, education and social welfare. Upon arrival clients were registered at a reception station for each village and their screening form from the previous day retrieved. The screening form laid the basis for the clinic the client was sent to, e.g. a client identified as having a "seeing" difficulty was sent to the 
ophthalmology clinic. A rehabilitation team led by the technical expert from the district-level services in that field was stationed at each clinic. This was to ensure continuity of care. The client underwent a comprehensive examination and received appropriate services including referral to a facility for on-going rehabilitation services. The referrals were done to facilitate access to rehabilitation care services and by so doing, fulfil ethical requirements. All assessment forms for PWDs were handed over to the district rehabilitation department to enable client follow-up.

\section{Analysis}

Data from the screening instruments and rehabilitation assessment forms were entered into Microsoft Excel version 4.0. Population data were enumerated by age and gender for each village from the "Profile of a CBR Area" and tallied against the enumeration data obtained during the door-to-door survey. Descriptive statistics were computed to characterize the demographics of PWDs. Proportions were computed to summarize the activity limitations.

\section{Results}

The population of the studied sites disaggregated by district, adult/child and the proportion of the population with a disability in these sub-groups is shown in Table 1. All households and all members of the villages in the studied districts agreed to participate.

The distribution of PWDs disaggregated by adulthood/childhood, village and gender is shown in Table 2.

Table 3 illustrates the distribution of activity limitations in children with disabilities (CWDs) in the two districts. Each child identified as having a disability could present with more than one activity limitation, therefore the table illustrates the frequency of each activity limitation in the CWDs. Fits referred to periodically occurring convulsions (including petit mal), and excluded fits caused by once-off temperature spikes. Fits were considered indicative of epilepsy (although the diagnostic label was not used), and therefore not truly an activity limitation. Therefore the category "strange behavior" was added. During the rehabilitation assessment interviewers probed to evaluate whether the described behaviour was a sign of mental ill health.

Activity limitations related to seeing functions were the most frequent in both districts.

Table 4 illustrates the frequency of activity limitations in adults with disabilities (AWDs) in the two districts. Likewise, AWDs could present with more than one activity limitation. Hearing in adults was erroneously omitted in the translated instrument and findings about hearing as an activity restriction in adults, were therefore not collected.

\section{Discussion}

This survey is the first of its kind in Rwanda, which describes disability using modern concepts of activity limitation in human functioning. Higher than previously reported prevalence rates for disability in Rwanda that range between 4\% and 5\% [9,12] were obtained. The survey questions at activity level of the ICF were more sensitive to identify disability compared to the impairmentlevel type of questions of the 2002 census and support the recommendation of including questions based on the ICF domains in epidemiological studies about disability [2].

Rwanda is the most densely populated country in Africa, with a density of $467 / \mathrm{km}^{2}$ and a population projected to be just over

Table 2. Distribution of persons with disability (PWDs) by age group and district $(n=349)$.

\begin{tabular}{|c|c|c|c|c|c|c|}
\hline \multirow[b]{3}{*}{ Children } & \multicolumn{3}{|c|}{ Bugesera } & \multicolumn{3}{|c|}{ Musanze } \\
\hline & \multicolumn{6}{|c|}{ Frequency $(\%)$} \\
\hline & Male & Female & Total & Male & Female & Total \\
\hline & $27(54.0)$ & $23(46.0)$ & $50(100)$ & $27(60.0)$ & $18(40.0)$ & $45(100)$ \\
\hline Adults & $42(46.7)$ & $48(53.3)$ & $90(100)$ & $63(38.4)$ & $101(61.6)$ & 164 (100) \\
\hline Total & $69(49.3)$ & $71(50.7)$ & $140(100)$ & $90(43.1)$ & $119(56.9)$ & 209 (100) \\
\hline
\end{tabular}

Table 3. Profile of activity limitation among children with disabilities (CWDs) by district $(n=95)$.

\begin{tabular}{lcc}
\hline & \multicolumn{2}{c}{ Frequency (\%) } \\
\cline { 2 - 3 } Activity limitation & Bugesera & Musanze \\
\hline Feeding-sucking & $9(6.3)$ & $3(3.7)$ \\
Hearing & $14(9.9)$ & $11(13.6)$ \\
Seeing & $24(16.9)$ & $19(23.5)$ \\
Sitting & $16(11.3)$ & $5(6.2)$ \\
Crawling & $15(10.6)$ & $5(6.2)$ \\
Walking & $19(13.4)$ & $8(9.9)$ \\
Talking & $14(9.9)$ & $6(7.4)$ \\
Fits & $6(4.2)$ & $10(12.3)$ \\
Strange behaviour & & \\
Learning & $15(10.6)$ & $14(17.3)$ \\
Total & $10(7.0)$ & $81(100)$ \\
\hline
\end{tabular}

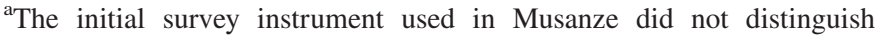
between "fits" and "strange behaviour".

Table 4. Profile of activity limitation in adults with disabilities (AWDs) by district $(n=349)$.

\begin{tabular}{lcr}
\hline & \multicolumn{2}{c}{ Frequency (\%) } \\
\cline { 2 - 3 } Activity limitation & Bugesera & Musanze \\
\hline Feeding & $8(4.8)$ & $6(2.3)$ \\
Sitting & $17(10.3)$ & $14(5.3)$ \\
Talking & $10(6.1)$ & $6(2.3)$ \\
Washing & $13(7.9)$ & $12(4.5)$ \\
Walking & $35(21.2)$ & $67(25.4)$ \\
Seeing & $37(22.4)$ & $84(31.8)$ \\
Getting dressed & $6(3.6)$ & $9(3.4)$ \\
Toileting & $11(6.7)$ & $21(8.0)$ \\
Strange behaviour & $28(17.0)$ & $45(17.0)$ \\
Total & $165(100)$ & $264(100)$ \\
\hline
\end{tabular}

Table 1. Profile of the population and disability prevalence by age group and district.

\begin{tabular}{|c|c|c|c|c|c|c|}
\hline \multirow[b]{2}{*}{ District } & \multicolumn{3}{|c|}{ Population, frequency $(\%)$} & \multicolumn{3}{|c|}{ Persons with a disability, frequency (\%) } \\
\hline & Children $^{\mathrm{a}}$ & Adults & Total & Children & Adults & Total \\
\hline Bugesera & $762(46.9)$ & $862(53.1)$ & $1624(100)$ & $50(6.6)$ & $90(10.4)$ & $140(8.6)$ \\
\hline Musanze & $582(41.0)$ & $837(59.0)$ & $1419(100)$ & $45(7.7)$ & $164(19.6)$ & $209(14.7)$ \\
\hline Total & $1344(44.2)$ & $1699(55.8)$ & $3043(100)$ & $95(7.1)$ & $254(14.9)$ & $349(11.5)$ \\
\hline
\end{tabular}

${ }^{\mathrm{a} C h i l d r e n ~ w e r e ~ t h o s e ~ y o u n g e r ~ t h a n ~} 18$ years of age. 
11 million in 2012 [14]. In 2010 the real GDP was $4.5 \%$ and at the time of going to press in 2012, the GNP is US $\$ 6583$ billion [10]. Over $90 \%$ of the population in these districts is engaged in agriculture. Around $65 \%$ of the families live below the poverty datum line [10]. In a general sense the features reported in the literature that intrinsically link poverty to disability [12] are true for Rwanda. Over and above this scenario, the 1994 genocide in Rwanda resulted in increased disability, not only as a direct result of the violence but also because of the breakdown of health, vaccination and rehabilitation services [15]. The genocide of 1994 is the most recent and most frequently reported, though a number of wars dog Rwanda's history during the last century. As is typical of wars, the genocides left survivors with disabilities, widows and orphans. As most of the killing was done by machete, many of those who did not die were left with disabilities - limbs amputated and widespread trauma [9], both physical and psychological.

Prevalence rates of $8.6 \%$ (Bugesera) and 14.7\% (Musanze) were found. The higher prevalence in Musanze could be attributed to the resurgent and repetitive conflict that continued to take place up until 1998. Including participation-level outcomes in addition to the current activity limitation may yield even higher levels of disability in Rwanda, though these findings provide sufficient and strong evidence for the need for rehabilitation services in the country.

Comparing disability prevalence across studies is difficult, mainly because of differences in the conceptualization of disability and subsequent differences in measurement instruments. A more deliberate intent to base outcomes on the International Classification of Disability, Health and Functioning (ICF) may facilitate cross-country comparisons in the future [16]. Still, comparisons give a sense of perspective about the level of disability in different contexts. A disability prevalence rate of $8 \%$ was reported in Tanzania [17], similar to the rate in Bugesera. Almost half as low a rate of $4.9 \%$ was found in Northern Ethiopia [18]. This low prevalence could be explained by the absence of the categories of questions related to feeding, sitting, washing, getting dressed and toileting, in the Ethiopian survey, but were included in the Rwanda study. The Ethiopian study did not include questions related to behavioural and mental health problems. Furthermore, the Ethiopian study asked about deafness and blindness, compared to questions about hearing and seeing in this study. If the current study's questions were used in Ethiopia, they would pick up partial deficits in these special senses in addition to deafness and blindness per se.

In both districts in Rwanda the prevalence of disability was higher in adults than in children. This is a general tendency partially explained by aging itself. For example in South Africa, the younger age group had a lower prevalence, where $2.1 \%$ of persons aged zero to nine years were reported as disabled. This percentage increased to $4.9 \%$ among persons aged 30 to 39 years, and increased to $27.2 \%$ for those aged more than 80 years [19]. Low prevalence levels of disability of between $0.32 \%$ and $0.22 \%$ in Malaysian children aged between 7 and 18 years are probably due to limitation in the study as acknowledged by the authors: "many items in the survey questionnaire are subjective and are based only on families' experiences, perceptions and may [be] subject to recall bias. Some other equally important areas such as the impact on the psychosocial health were not included' [20]. In Zimbabwe, the average individual with a disability is seven years older than the average individual without a disability (mean age: 41 versus 31 years) [21]. While rehabilitation services for children are essential, the findings in Rwanda also support the importance of rehabilitation service as part of comprehensive health care for adults and senior citizens.
The ratio of male to female disability is similarly distributed in both districts studied in Rwanda. The 2001 South African census showed that in males and females the prevalence of disability was $5.1 \%$ and $5 \%$, respectively [19]. However, in Zimbabwe, disability prevalence for women was higher than that of men (12.9\% versus $9 \%$, respectively) [21]. In the latter case, this may be explained by the fact that women are more readily involved in development projects at the community level [22] and therefore more easily reached in surveys of this kind. This may have been the case in this Rwandan study that was carried out during the day. Further, women have been reported to have better health seeking behaviours than men [23] and are more likely to be identified as needing services in community surveys.

In both adults and children and in both districts, seeing was the most prevalent type of disability, with walking following very closely in Bugesera. Limitation in vision has similarly been reported as the leading type of disability in several countries in sub-Saharan Africa, including Zimbabwe [21], Zambia [5] and South Africa [19]. One significant implication of high levels of visual limitation is the need for mobility training [24], including the provision of the appropriate mobility aids.

In both districts, "strange behaviour" was the third most frequent cluster of activity limitation. This finding represents significant morbidity in a domain that is subject to high stigma and often considered hidden morbidity [25]. In a previous report, written 15 years after the genocide in Rwanda, $50 \%$ of participants in a study met the criteria for psychiatric disorder [15]. Reporting on a survey in peri-urban Zimbabwe, Jelsma [26] diagnosed one third of the people enumerated in a house-to-house survey with depression. The conditions that give rise to this growing burden of ill-health attributed to mental health disorders falls beyond the scope of this paper, but is discussed liberally in the literature. Suffice to say that rehabilitation services need to respond to prevention, care and mitigating the impact of mental health disorders, and their impact on the caregivers.

The difference in disability prevalence between the two districts, highlights that, randomly sampling districts from a country like Rwanda, may not generate data that can be reliably generalized to the country as a whole. The truer picture that emerges from surveying individual districts may warrant the extra time and effort from the research team's side, as the findings can more accurately inform policy and service development. Rather than a limitation, purposive sampling in the case of disability prevalence studies may give data that is better able to inform prioritization of the development of services where resources are few.

We employed the use of four instruments to collect data in this study - profile of the CBR area, the home entry questionnaire, the adult and child disability screening tools and the rehabilitation assessment form. The combined use of these instruments and the procedures followed enabled adherence to the ethical standards of giving information, privacy, beneficence and accuracy.

The profile of the CBR area collected population data. This was used to validate enumeration of the population in each village done during the survey, and was used to calculate the disability prevalence. This instrument also collected data on health, education and rehabilitation services available in the area. Handicap International refers to these aspects as political grounding [27], because the goal for conducting disability surveys is to improve the living conditions and enhance the choices of PWDs. Consequently, in order to make evidence-based decisions and define policies and programmes, it is important to have reliable insights into the living conditions of the PWDs.

The ICF framework informed the screening tools. The ICF is recognised as being able to capture and describe human functioning, and thus define disability [4]. It therefore provides 
a good basis for construction of a screening questionnaire [28]. The definition of disability was translated into precise and relevant questions to constitute the screening tools $[4,28]$. These screening tools identified different types of disability from a large number of participants in a cost-effective and efficient manner. Although more than one surveyor was involved in identifying and screening for disability in each household, and we combined the use of health and social rehabilitation workers in the survey team to compensate for the short training period; we further validated the findings from the screening tool with the assessment form. Various sources of information may be used to determine the presence of disability [27], we selected the screening tool with an assessment as validation over self-identification, estimates based on diagnosable conditions and performance of ADLs as they have been reported to tend to yield lower rates of disability [4].

Although information from the rehabilitation assessment provides information about involved body structures and body function (impairment level of the ICF), results were not available for publication at the time of writing due to administrative and ethics requirements. The National Institute of Statistics of Rwanda subjects such survey data to specific internal processes prior to approving it for publication.

Causes and severity of disability, distinction between capacity and performance of activities that were not considered in the current study, should be included in future research. In the questionnaire for children, activity-level domains like object and peer play, caregiver and child interaction, and pre-verbal communication should be included in follow-up studies [28].

Results of this study could be complemented with follow-up survey collecting further information included in the ICF, specifically participation restrictions and the influence of environmental factors [6].

\section{Conclusion}

Up to the time of this study estimates about the number of PWDs in Rwanda were confined to census data, which tends to underestimate prevalence rates. This cross-sectional study determined the prevalence of disability in two purposefully selected provinces in two age categories: CWDs from zero to 18 years, and PWDs older than 18 years. Questions in the survey instrument sought information on activity-level restrictions like feeding and talking. In Bugesera, the prevalence of disability was $6.6 \%$ for CWDs and $10.4 \%$ for AWDs. Musanze district, where violence erupted after the 1994 genocide, had higher rates of $7.7 \%$ and $19.6 \%$ respectively. Seeing, mobility and mental functions were by far the most prevalent disabilities. This study marks the first time that concepts from the ICF framework have been used to describe the distribution of disability in Ruanda and the first time that PWDs and lay community members participated in the process to the extent described in this paper.

Nonetheless, going forward, future enquiry to determine the causes of the disabilities observed, alongside addressing the limitations outlined in this study will provide even more useful information for planning, prioritising and directing services and resources for rehabilitation in Rwanda.

\section{Acknowledgements}

We thank the communities that participated in this study. We acknowledge the contribution of the fourth-year Physiotherapy Honours classes' of 2010 and 2011 from Kigali Health Institute, the rehabilitation team from Ruhengeri District Hospital, Nyamata District Hospital, Handicap International Rwanda and Rilima Rehabilitation Centre for data collection and collation. Gratitude is extended to Julia Chevan for proofreading the manuscript.

\section{Declaration of interest}

Funding was made available by the Kigali Health Institute in both districts and further assistance given by Rilima Rehabilitation Centre in Bugesera, through an Italian technical grant.

\section{References}

1. The World Health Organization. World Report on Disability 2011. Available from: http://whqlibdoc.who.int/publications/2011/ 978924085215_eng.pdf [last accessed 11 Jun 2012].

2. Mont D. (2007). Measuring Disability. Special Discussion Paper. World Bank No. 0706.

3. Mclaren PA, Gear SS, Irwigan LM, Smit AE. Prevalence of motor impairment and disability in a rural community in KwaZulu. Int Rehabil Med 1987;8:98-104.

4. Australian Institute of Health and Welfare (AIHW). Disability prevalence and trends. Disability series. 2003. AIHW Cat. No. DIS34. Canberra: AIHW.

5. Eide $\mathrm{AH}$, Loeb $\mathrm{M}$, eds. Living conditions among people with activity limitations in Zambia: a national representative study. SINTEF Health Research. 26 August 2006. The Norwegian Federation of Organizations of Disabled People Project 78g026 Report No. STF78 AO4451.

6. Virués-Ortega J, Pedro-Cuesta J, Seijo-Martinez M, et al. Prevalence of disability in a composite $\geq 75$ year-old population in Spain: a screening survey based on the International Classification of Functioning. BioMed Central (BMC) Publ Health 2011;11:176-87.

7. Mayhew L. 2001. Disability - global trends and international perspectives. Paper presented to the Staple Inn Actuarial Society at Staple Inn Hall London on 4 December 2001. Available from: www.sias.org.uk/data/papers/Disability/DownloadPDF [last accessed 11 Jul 2012].

8. Republic of Rwanda. Law 01/2007 of 20 January 2007. Law Instituting Protection of Disabled Persons. Official Gazette of the Republic of Rwanda, Kigali.

9. National Institute of Statistics of Rwanda. How many are we in Rwanda? Available from: http://www.statistics.gov.rw/publications/ article [last accessed 11 July 2012].

10. Economy Watch. 2012. Economic statistics and indicators. Available from: http://www.economywatch.com/economic-statistics/year/2012/ [last accessed 11 June 2012].

11. UN Enable. c. Convention and Optional Protocol Signatures and Ratifications. Available from: http://www.un.org/disabilities/ countries.asp?navid=12\&pid=166 [last accessed 8 Mar 2012].

12. Thomas P. Disability, poverty and the millennium development goals: relevance, challenges and opportunities for DFID. Available from the Gladnet Collection at DigitalCommons@ILR, Cornell University ILR School. Available from: http://digitalcommons.ilr.cornell.edu/gladnetcollect/256 [last accessed 2 Dec 2012].

13. Ministry of Health and Child Welfare Zimbabwe. Guidelines on Implementing Community Based Rehabilitation in Zimbabwe. A practical manual. Revised 2002. Available at the University of Zimbabwe College of Health Sciences, Department of Rehabilitation Library.

14. National Institute of Statistics of Rwanda. 2012. Counting the people of Rwanda - 2012 Population and Housing Census. Mapping for the 2012 Rwandan General Population and Housing Census - How many are we in Rwanda? Available from: http://statistics.gov.rw/ publications/counting-people-rwanda-2012-population-and-housing-census-phc [last accessed 30 Nov 2012].

15. Ingrid L. Education for disabled people in Ethiopia and Rwanda. Background paper for the Education for All Global Monitoring Report 2010. UNESCO. 2010/ED/EFA/MRT/PI/01.

16. Leonardi M. The European MHADIE project. Disabil Rehabil 2010; 32:S1-S8.

17. Njelesani A, Couto S, Cameron D. Disability and rehabilitation in Tanzania: a review of the literature. Disabil Rehabil 2011;33: 2196-207.

18. Tamrat G, Kebede Y, Alemu S, Moore J. The prevalence and characteristics of physical and sensory disabilities in Northern Ethiopia. Disabil Rehabil 2001;23:799-804.

19. Statistics South Africa. Prevalence of disability in South Africa: census 2001. Available from February 8, 2012, from www.statssa.gov.za 
20. Khoo T, Kassim AAB, Omar MA, et al. Prevalence and impact of physical disability on Malaysian school-aged children: a populationbased survey. Disabil Rehabil 2009;31:1753-61.

21. Mitra S, Posarac A, Vick, B. Disability and poverty in developing countries: a snapshot from the World Health Survey. Washington: World Bank, 2011. Special Discussion Paper No. 1109. Available from: http://www.wds.worldbank.org/ external/default/WDSContentServer/WDSP/IB/2011/06/ 0000386194201106

22. Ajayi R, Otuya N. Women's participation in self-help community development projects in Ndokwa agricultural zone of Delta State, Nigeria. Comm Dev J 2006;41:189-209.

23. Ahsan G, Ahmed J, Singhasivanon P, et al. Gender differences in treatment seeking behaviours of tuberculosis cases in rural communities of Bangladesh. Southeast Asian J Trop Med Public Health 2004;35:126-35.
24. League of the Blind. Disability statistics. Available from: http:// www.tanzanialeagueblind.org/news.php [last accessed 11 Jun 2012].

25. Lund C, Stein DJ, Corrigall J, et al. Mental health is integral to public health: a call to scale up evidence-based services and develop mental health research. South Afr Med J (SAMJ) 2008;98:444-6.

26. Jelsma J, Meilke J, Powell G, et al. Disability in an urban black community in Zimbabwe. Disabil Rehabil 2002;24:851-85.

27. Handicap International. Conducting surveys on disability: a comprehensive toolkitNational disability survey in Afghanistan, 2005. Available from: http://www.handicap-international.fr/bibliographiehandicap/7Donnees/RapportEtude/toolkit_NDSA.pdf [last accessed 6 Mar 2013].

28. Simeonsson RJ, Leonardi M, Lollar D, et al. Applying the International Classification of Functioning, Disability and Health (ICF) to measure childhood disability. Disabil Rehabil 2003;25: 602-10. 